Article

\title{
Selection Methodology of an Electric Actuator for Nose Landing Gear of a Light Weight Aircraft
}

\author{
Taimur Ali Shams ${ }^{1, *,+}+{ }^{+}$, Syed Irtiza Ali Shah ${ }^{1, \dagger}$, Muhammad Ayaz Ahmad ${ }^{1, \dagger}$, \\ Kashif Mehmood ${ }^{1,+}$, Waseem Ahmad ${ }^{1,+}+$ and Syed Tauqeer ul Islam Rizvi $^{2,+}$ \\ 1 Department of Aerospace Engineering, College of Aeronautical Engineering, National University of Sciences \\ and Technology, Islamabad 44000, Pakistan; irtiza_shah@gatech.edu (S.I.A.S.); \\ mayaz@cae.nust.edu.pk (M.A.A.); kmehmood@cae.nust.edu.pk (K.M.); Waseem.hashmii@yahoo.com (W.A.) \\ 2 Aerospace and Aviation Campus, Air University, Kamra, District Attock 43600, Pakistan; \\ tauqeerulislam@aack.au.edu.pk \\ * Correspondence: taimur.shams@cae.nust.edu.pk; Tel.: +92-3244097152 \\ + All authors contributed equally to this work.
}

Received: 3 November 2020; Accepted: 30 November 2020; Published: 6 December 2020

check for updates

\begin{abstract}
Landing gear system of an aircraft enables it to take off and land with safety and comfort. Because of the horizontal and vertical velocity of aircraft, upon landing, the complete aircraft undergoes different forcing functions in the form of the impact force that is absorbed by landing gears, shock absorbers, and actuators. In this research, a selection methodology has been proposed for an electrical actuator to be installed in the retraction mechanism of nose landing gear of an aircraft having $1600 \mathrm{~kg}$ gross takeoff weight. Nose landing gear and its associated components, like strut and shock absorbers, were modeled in CAD software. Analytical expressions were then developed in order to calculate the actuator stroke, translational velocity, force, and power for complete cycle of retraction, and some were subsequently compared with the computational results that were obtained using MSC ADAMS ${ }^{\circledR}$. Air in the oleo-pneumatic shock absorber of nose landing gear was modeled as a nonlinear spring with equivalent spring constant, whereas hydraulic oil was modeled as a nonlinear damper with equivalent damping constant. The nose landing gear system was modeled as a mass-spring-damper system for which a solution for sinusoidal forcing functions is proposed. Finally, an electrical actuator has been selected, which can retract and extend nose landing gear, meeting all of the constraints of aircraft, like fuselage space, aircraft ground clearance, locking loads, power consumption, retraction and extension time, and dynamic response of aircraft. It was found that the selection of an electrical actuator is based upon the quantification of forces transmitted to electrical actuator during one point load at gross takeoff weight. The ability of retraction and extension time, as dictated by Federal Aviation Regulation, has also been given due consideration in the proposed methodology as significant criteria. The proposed system is now in the process of ground testing, followed by flight testing in the near future.
\end{abstract}

Keywords: nose landing gear; retraction mechanism; electro-mechanical actuators; impact force; locking loads

\section{Introduction}

Landing gear system is one of the essential subsystem for aircraft operations that dampens the impact force during the landing phase of an aircraft by absorbing and dissipating kinetic energy, and it acts as a suspension system during taxi and takeoff mission segments [1]. It ensures that structural loads that are transferred to the air-frame of an aircraft are within allowable limits. The landing gear system also houses braking and steering systems for on ground speed reduction and directional 
control. Aside from the essential necessity of landing gear system, they are heavy on aerodynamics performance. They not only produce significant amounts of aerodynamic drag, but also add plenty of weight to the aircraft, which affects the aircraft performance parameters. The design of landing gear systems are constantly evolving not only to reduce aerodynamic drag, but also mitigate their overall negative impacts. Starting from a simple fixed-gear configurations in pre-WWI aircraft to the installation of fairings and, later, to retractable landing gears, their designs have revolutionized aircraft performance. The landing gear system design process is a complex process in which the designer has to overcome many constraints, including minimum volume, minimum weight, short development cycle, and reduced life cycle cost. In addition, various requirements of ground clearance, stability, stiffness, control, and damping of impact force under all possible landing conditions of aircraft also demand significant attention [2]. From an aerodynamics perspective, landing gear design constraints are weight and drag reduction during the design process. The retraction design leads to a significant aerodynamic drag reduction, while the fairings alone design feature also promise large savings on drag, but they add to landing gear's weight and complexity [3]. Small aircraft, mainly unmanned aerial vehicles (UAVs), are opted for fixed landing gears system in order to avoid the potential design complexity and weight penalties that can severally effect the payload capabilities. However, recent research has shown that landing gear drag can be as high as $15-28 \%$ of a UAV's total parasite drag. Consequently, the designers now have to weigh the potential benefits of retraction system by avoiding a huge chunk of drag versus the additional weight, which is approximately $10 \%$ of aircraft structural weight [4]. Designers are looking for alternate systems to the conventional hydraulic retraction mechanism for reducing the associated weight penalty. The rapid advancement during recent years in the field of electric drives has provided new opportunities in improving the performance of an aircraft at all levels from production, serviceability, maintainability to environmental footprint, fuel burn, and safety [5]. Generally, conventional actuation systems for critical safety applications, like landing gears, are dependent on hydraulic power and need distribution system along with centralized hydraulic power, which make the system very complex. In this situation, electric drives offers a very effective solution to remove the conventional actuation drawbacks by offering new opportunity for performance improvement [5]. Moreover, recent researchers have concluded that electric actuation systems also contribute in weight savings significantly. All of these factors contribute to the reduction of operational cost in comparison with existing aircraft. Electrically driven actuation systems have already been extensively tested and researched for the purpose of actuation in aircraft critical subsystems, like flight control, and are being used on "Airbus A380" and "Boeing 787" as backup flight control actuators. The Boeing 787 and many other aircraft are also using electro-mechanical actuators for brakes and landing gear locks. A "local electro-hydraulic generation system" (LEHGS) is being used as backup for the purpose of steering and nose landing gear actuation in Airbus A380, but landing gear actuation on this aircraft still has numerous hydraulic power sources [6]. Small aircraft or Unmanned Ariel Vehicles (UAVs) usually rely on electrically operated flight control systems instead of conventional Flight control. In such a scenario, landing gear would be the only component requiring hydraulic system for its operation if not shifted to an electrically operated actuation system, which is far from optimized aircraft design philosophy [7]. Hence, the present research work aims to select a landing gear retraction mechanism for nose landing gear that is based on electric drive, which meets all of the design requirements.

In recent years, there is a trend of increased use of the electric actuation system in the aerospace, which is known as power-by-wire (PBW) Electric Aircraft actuation. There are different approaches of PBW technologies and applications, which are extended to landing gear, flight control, actuation system, and Thrust Vector Control (TVC) [8]. The requirement and functional need of actuation in landing gears are different, which includes the rising and lowering the landing gears, wheel braking, and nose-wheel steering [9]. The primary limitation toward electrically actuated landing system lies in aircraft safety. Decades of working experience with hydraulics in automobiles and aircraft has made it reliable and safe for operations. Owing to the use of conventional actuation systems for quite a long time, a lot of 
industrial innovations have been made in the development of these actuation systems. Moreover, a lot of technical expertise is also available for the maintenance of these systems. Despite these advantages, peculiar risks are always associated with the use of hydraulic as a power source. The risk of fire from the inflammable fluids used in the system and their general messiness bring a lot of criticism to the use of hydraulic in the aircraft system. Moreover, the desire to lessen aircraft airframe noise and weight has shifted the balance in favor of the electrical actuation mechanism. They are designed to run more efficiently at extreme temperature ranges when compared to the hydraulic, which requires specific temperature ranges for effective working. The use of electrical actuators will additionally give the capability to lessen the maintenance and operational costs. The Electro-Mechanical Actuator (EMA) mostly consists of "Mechanical Drive Assembly" (i.e., an actuator module, which includes mechanical components and a servomotor), which helps in converting the electrical energy to mechanical energy, and an "Electronic Control Unit (ECU)", which is required for control signals and power. Figure 1 shows the basic layout of an EMA. The power control box and electronic control box, combined, make up the ECU of the actuator, while the motor, gearbox, and screw mechanism make up the mechanical drive assembly of actuator.

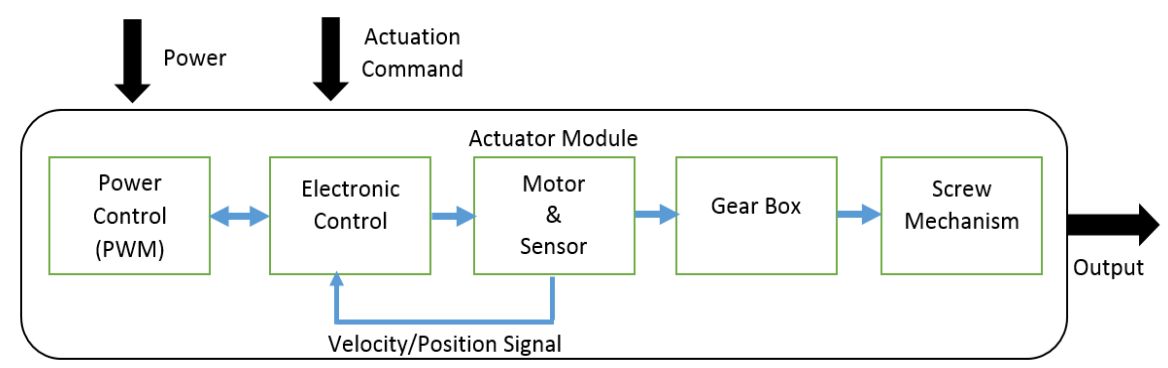

Figure 1. Electro-mechanical Actuator (EMA) schematic. This figure identifies the components of an electro-mechanical actuator.

Electrical motor is the fundamental part of electro-mechanical actuator that coverts the electrical energy to mechanical energy. The motor selection usually depends upon the available power supply. Permanent Magnet Synchronous Motor (PMSM) is the best option for the system in which AC power source is directly available [8]. It is used to control the direction and speed of winding by the electric switch, which, in turn, is controlled by electronic power devices. The servo motor have compatibility of high speed with high power density, and also offers high reliability with good heat dissipation which is the most important requirement of the flight control system. Although, there are many types of motors that are suitable, but four common motors options are as follows:

- the Switched Reluctance (SR) motor;

- the Brushless DC motor;

- $\quad$ permanent Magnet Synchronous Motor (PMSM); and,

- $\quad$ brushed DC motor.

A gearbox is used in order to transform low torque and high speed from the servo motor of actuator mechanism into low speed and high torque. Different types of gearbox, like Harmonic, cycloidal, or planetary gearboxesm are used for this purpose. However, planetary gearboxes are an effective selection, since their compact design uses less space and provide high effectiveness. A large part of the actuator mass can be dedicated to the servo motor when using planetary gearboxes because of its low gear ratio, as compared to the high reduction ratios of cycloidal and harmonic reducers. Next to the gear box, a screw mechanism is used in order to convert rotary motion into linear motion with a required force by transforming the torque and speed of servo motor. There are three primary kinds of linear actuation, which function by using a lead, roller, or ball screw. The Electronic Control Unit (ECU) controls the EMA module, which can run on $28 \mathrm{~V}-\mathrm{DC}$ power source. The power 
control system of ECU defines the pulse width modulation for the motor control in the response to a torque command signal or position signal. The sensors in EMA directs the position, load and speed information towards the ECU for the feedback of landing gear position. For the flight state in which the external loads on landing gear actuator are high, an extra sensor for measuring the temperature is installed, so that the temperature of electronic components can be recorded and if the temperature is high, the ECU can let the components to cool down by limiting the current and voltage within range and give feedback about high temperature.

\section{Regulations on Landing Gear Retraction Mechanisms}

There are many design requirements regarding the landing gear retraction mechanism. High reliability, along with safety, minimal weight, low manufacturing cost, and proper maintainability, are all demanded. These necessities are conflicting in several factors. However, some priorities do also exist which are clearly dictated by the airworthiness authorities. The civil aviation regulations/directives that governs the design features for retractable landing gear mechanism, which the designer must comply for the certification and safety purpose states that the landing gear retraction mechanism along with its supporting structure must be designed for maximum of the flight load elements with the gear being retracted. They should be designed to deal with the combination of air loads, friction, brake torque, and inertia occurring for the whole duration of retraction at any airspeed up to 1.6 times the velocity with flaps retracted, moreover aside from the flight loads, they should be able to withstand the loads due to all yawing conditions with the touchdown gear extended. Stability is an other important issue to be addressed while designing landing gear system. The stability characteristics of a system strongly depend on the level of non-linearity and time dependence of the governing equations [10]. While designing, dynamic forces between the tires and ground during high-speed taxiing should be given importance, as they cause instability in high speed performances that can damage the landing gear of the aircraft and its fuselage [11]. It is suggested that, aside from the use of an actuator, there must to be some other mean to maintain the landing gear at extended position during landing and for an aircraft having a retractable landing gear system that cannot be set to extended position manually, there must be some secondary way to extend the landing gear in the emergency occasion due to any possible failure in the normal operation of landing gear retraction system. The aviation regulations further suggest that, if landing gear is retractable, then there should be a position indicator for landing gear in addition to essential switches or there must be use of some other approach to inform the pilot (or ground control station in case of Unmanned Aerial Vehicle) that every gear is securely in its retracted or extended position [12]. For airworthiness authorities, there is no compromise over safety in any sense during the landing gear actuation mechanism design due to the extreme outcomes of failure. From the above evaluation, it has been concluded that at least a two stage power source redundancy level must be incorporated in the system for safety, and it will be enough to satisfy the airworthiness requirements. For actuation purposes of landing gear, the subsequent fail-safe design factor must also be incorporated within the system by using a secondary motor in actuator design, so that:

- $\quad$ with the help of primary motor, the time requirement for retraction must be fulfilled; and,

- in the case of primary motor failure, the secondary motor must be able to provide enough torque for extending and retracting the landing gear.

\section{Proposed Methodology}

The retraction mechanisms of landing gear system is composed of three parts [13]

- a hardware that contains all mechanical components and landing gears structure;

- an electrical control system including control software; and,

- pilot interface. 
Designing the retraction mechanism for landing gear system is a highly tedious job and it requires a lot of focus. The kinematics, along with geometry parameters of the landing gear system, are dependent on aircraft design features and, therefore, is specific to every aircraft. In design methodology designer has to follow the constraints that are imposed by the aircraft design in terms of weight, space, location, and mission requirements, etc. Some of the constraints that are offered by the aircraft design in this work are listed below in Table 1. Moreover, the landing gear should be structurally capable of withstanding impact loading at touchdown and remaining in extended position. The loads acting on the landing gear are divided into the following categories: [14]

- $\quad$ aerodynamic forces;

- $\quad$ externally applied forces i.e., torques;

- mass forces i.e., gravity; and,

- impact loads

Table 1. Design constraints.

\begin{tabular}{ll}
\hline Parameter & Value \\
\hline Maximum takeoff weight & $1600 \mathrm{Kg}$ \\
Maximum fuel capacity & $380 \mathrm{Kg}$ \\
Mass of nose landing gear strut & $13 \mathrm{Kg}$ \\
Length of nose landing gear strut & $110.50 \mathrm{~cm}$ \\
Approach speed of aircraft & $36.01 \mathrm{~m} / \mathrm{s}$ \\
Sink speed & $2.63 \mathrm{~m} / \mathrm{s}$ \\
Maximum horizontal approach speed & $35.92 \mathrm{~m} / \mathrm{s}$ \\
Maximum retraction angle & $88^{\circ}$ \\
Maximum retraction time during normal operation & $15 \mathrm{~s}$ \\
Angle of landing gear at fully extended position & $97.61^{\circ}$ \\
Power source voltage available on-board & $28 \mathrm{~V}$ \\
\hline
\end{tabular}

In this work, a comprehensive selection methodology of landing gear actuator has been presented, as per the FAR 23 standards. Various certification requirements for the landing retraction cycle have been discussed in detail and time dependent analytical equations have been derived. The analytical equations are then verified after retraction analysis on MSC ADAMS. The final form of these analytical equations can be utilized in order to calculate various parameters of retraction cycle for any landing gear with similar mechanism and identify the energy efficient actuator that consumes less power. Moreover a methodology has been presented for computational evaluation of impact force after modelling oleo-pneumatic strut on MSC ADAMS. The calculation of impact force is a very critical analysis in designing any retractable or fixed landing gear mechanism. In a retractable landing gear system, it is even more important to calculate the exact force acting on the actuator and its locking mechanism during landing, so that landing gear might not collapse or retract back to fuselage during impact. A kinematic design has been proposed for the retraction mechanisms of a light weight aircraft and analytical equations were developed for the retraction/extension cycle to calculate the stroke and force requirements, as shown in Figure 2. While deriving the analytical equations, the translational velocity of landing gear was modelled as a quadratic function, which means that the lading gear will slowly start to retract and reach its maximum velocity in the first half of the retraction cycle, and then its velocity will start to decrease in the next half. If the retraction cycle was designed in such a way that the velocity increases gradually, a lot of stresses would have been introduced at the strut-actuator due to a sudden jerk at the start of retraction that is not usually considered to be a safe practice during design. The results were then also compared with the MSC ADAMS ${ }^{\circledR}$. There is very less possibility that the analytical and computational method can yield exactly the same results, so, usually, a less than 5 percent error can be considered to be acceptable in verifying the authenticity of analytical and computational method [15]. Once the retraction mechanism was developed, spring characteristic, and damping constants of oleo pneumatic shock absorber were calculated in otder to identify the 
horizontal and vertical impact on the landing gear and its effect on the actuator and locking mechanism to make sure that the landing gear will remain securely locked at its position and does not move undesirably at the time of impact during landing. Before finalizing the design, a FAR 23 check is required in order to verify the design standards. FAR 23 standards mostly dictates about the safety, like there should be redundant motor in the actuator and structure should be capable of taking load about 1.6 times the normal load, etc. Moreover, a FAR 23 check is required in order to figure out that weather CAD design have that much space for redundant motor. If the dead length of actuator is less than the standard that is required for motors and locking mechanism, then either the moment arm (M) must be increased or the Distance (D) must be increased in the Figure 1. Additionally, it must be made sure that landing gear meets the retraction time requirement as per the standard and the drop height is calculated according to the FAR 23 clause 23.725 that limits the drop height.

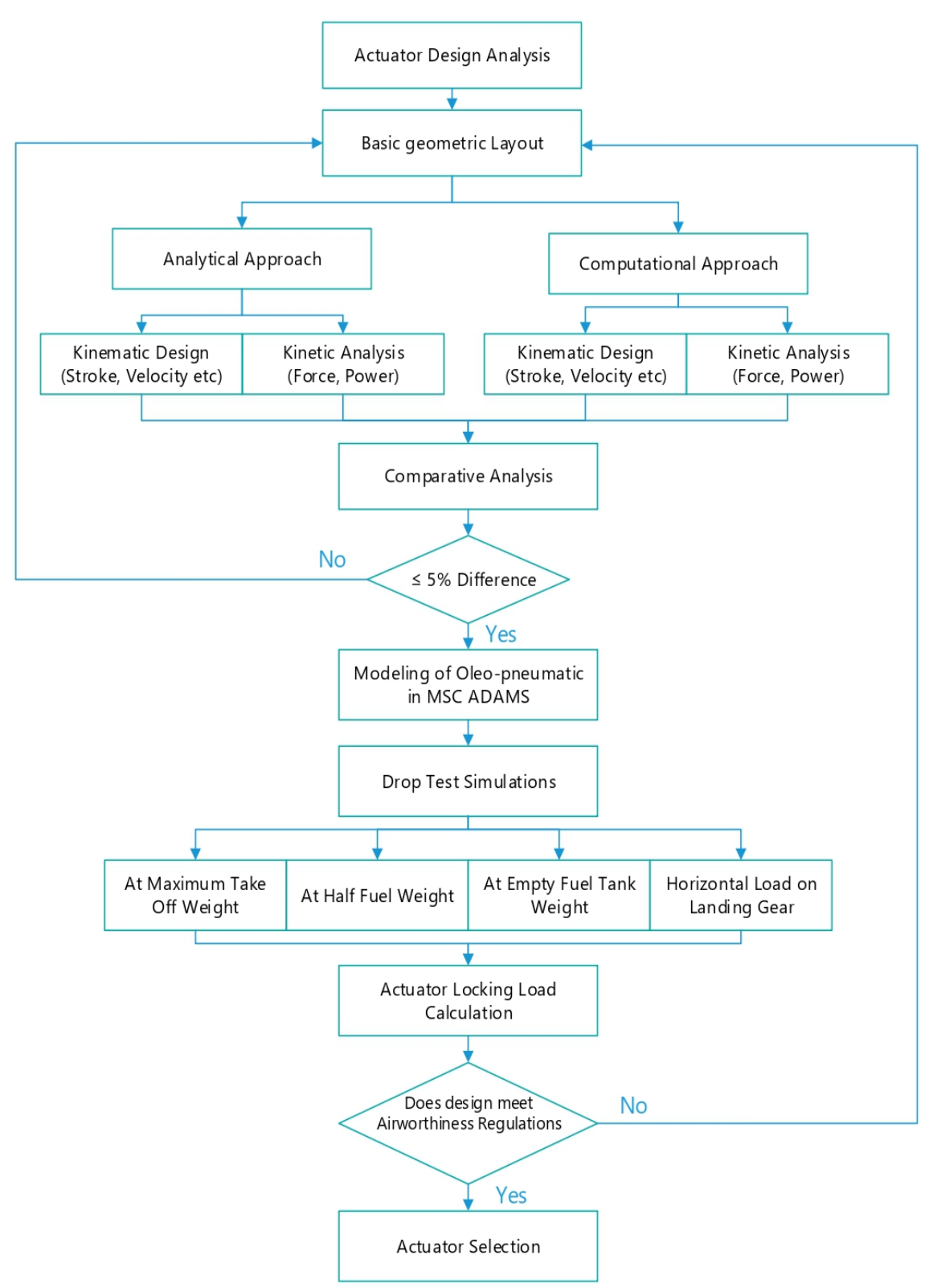

Figure 2. Proposed Selection Methodology. 


\section{Analysis}

\subsection{Analytical Approach}

For the purpose of analytical solution, planer kinematics have been used to design and evaluate the parts used to extend and retract the gear with the attention to geometry of landing gear in the retracted and extended position while planer kinetics has been used for the evaluation of power requirement by the landing gear [16]. Basic guidelines for theoretical approach suggests that starting from the geometrical layout, the designer must replace the system with a mathematical model, while doing so satisfactory moment arms must be ensured for actuation along with the simplest kinematics possible for actuation. The designer must make sure to approximate the proper actuator "dead length" in the design layout. Following are suggested values. With no internal lock, the dead length should be 6 to 7 inch. With one internal lock, the dead length should be 8-11 inch and, for two internal locks, dead length should be in range of 12 to 15 inch [17]. While deciding the time for retraction of gear, it must be kept in mind that gear need to be retracted before the airplane reaches 75 percent of its speed with maximum forward acceleration [18].

Figure 3 shows the required dimensions of landing gear for analytical solution of retraction. The landing gear was treated as rigid body while performing the theoretical calculations for the retraction system. Time dependent general equations for the landing system were developed that can be used for retraction of any landing gear with same mechanism.

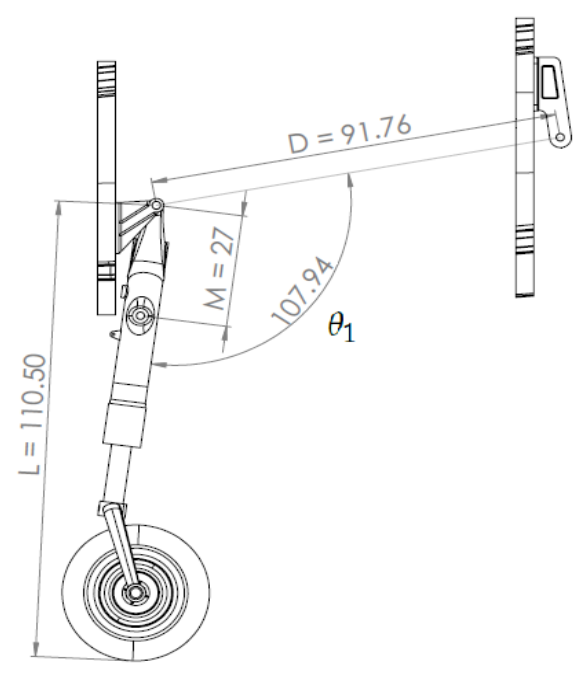

Figure 3. Nose Landing Gear dimensions for retraction mechanism (all dimensions are in $\mathrm{cm}$ ).

When fully extended, the landing gear is at an angle of 107.94 degree as shown in Figure 3. During retraction, the angle starts to decrease as a function of time, so angle $\theta$ at any position during retraction cycle is given as,

$$
\theta=\theta_{1}-\Delta \theta_{t}
$$

where $\theta_{1}$ is the initial angle of landing gear when fully extended and $\Delta \theta_{t}$ is the change in angle of landing gear at any given time $t$. The retraction sequence of nose landing gear when retracted slowly without jerks can be modeled as a quadratic polynomial instead of step function, so that the velocity increases slowly to its maximum value and then decreases. If $\dot{\theta}_{t}$ is the angular velocity of landing gear, then

$$
\dot{\theta}_{t}=c\left(t^{2}-t \times t_{\max }\right)
$$

Here, $c$ is the constant, whose value depends upon maximum retraction angle and time of nose landing gear and $t_{\text {max }}$ is the maximum time of landing gear retraction or extension sequence. 
By integrating angular velocity, a change in angle of retraction or extension can be obtained, as shown in Equation (3).

$$
\Delta \theta_{t}=c\left(\frac{t^{3}}{3}-\frac{t^{2} t_{\max }}{2}\right)
$$

For the $1600 \mathrm{Kg}$ aircraft considered in this research, nose landing gear retracts by $88 \mathrm{deg}$ in maximum time of $15 \mathrm{~s}$; therefore, if $t=t_{\max }=15 \mathrm{sec}$ and $\Delta \theta_{t}=88 \mathrm{deg}$, then by putting the values in (3), the value of c comes out to be -0.1565 , so

$$
\begin{aligned}
\Delta \theta_{t} & =-0.1564\left(\frac{t^{3}}{3}-\frac{t^{2} t_{\max }}{2}\right) \\
\dot{\theta}_{t} & =-0.1564\left(t^{2}-t^{2} t_{\max }\right)
\end{aligned}
$$

From the above equations, the desired angle and angular velocity of landing gear can be found at any time $t$. Applying law of cosine to the Figure 3 gives

$$
A_{t}^{2}=D^{2}+M^{2}-2 D M \cos (\theta)
$$

The length of actuator at any time $t$ is given by

$$
A_{t}=\sqrt{D^{2}+M^{2}-2 D M \cos \left(\theta_{1}-c\left(\frac{t^{3}}{3}-\frac{t^{2} t_{\max }}{2}\right)\right)}
$$

where, $A_{t}$ is the length of actuator, $D$ is the distance between actuator mount and landing gear strut mount, $M$ is the moment arm, and $\theta_{1}$ is the initial angle of landing gear when gears are in fully extended position. The length of an actuator $\left(A_{0}\right)$ at fully extended position is calculated by setting $t=0$ in Equation (7) and, at retracted position, the actuator length $\left(A_{t}\right)$ is calculated by setting $t=t_{\max }$. The actuator stroke $S_{A}$ is the difference in length of actuator, at the start of retraction cycle (extended position) and length of actuator at $t=t_{\max }$ (retracted position), so $S_{A}=A_{0}-A_{t}$. However, it is highlighted that some portion of actuator was reserved for internal components and room needed to physically come to the end-of-stroke. This is normally referred to as the actuator's "dead length" [19]. The dead length of actuator can be calculated as $A_{t}-S_{A}$. Because $D$ and $M$ in Equation (6) are constant, while only $A_{t}$ and $\theta$ changes during retraction, taking derivative of equation yields Equation (8),

$$
V_{s}=\frac{D M \sin (\theta)}{A_{t}} \times \omega
$$

where $\omega$ is the angular velocity whose value can be calculated after multiplying Equation (2) with $\frac{\pi}{180}$. Now, the final equation for the translation velocity can be derived after substituting the value of $\theta$, $A_{t}$ and $\omega$ in Equation (8).

$$
V_{s}=\frac{D M \sin \left(\theta_{1}-c\left(\frac{t^{3}}{3}-\frac{t^{2} t_{\max }}{2}\right)\right)}{\sqrt{D^{2}+M^{2}-2 D M \cos \left(\theta_{1}-c\left(\frac{t^{3}}{3}-\frac{t^{2} t_{\max }}{2}\right)\right)}} * \frac{c \pi}{180} *\left(t^{2}-t^{2} t_{\max }\right)
$$

Taking derivative of Equation (2) yields

$$
\begin{gathered}
\ddot{\theta}_{t}=c\left(2 t-t_{\max }\right) \\
\alpha=\frac{c \pi}{180}\left(2 t-t_{\max }\right)
\end{gathered}
$$


where $\alpha$ is the angular acceleration. Now, for the calculation of power, we need to know how the angle of actuator with respect to the strut changes during the retraction, so, if $\phi$ is the angle between the strut and actuator, then from Figure 3,

$$
\phi=\cos ^{-1}\left(\frac{D^{2}-M^{2}-A_{t}^{2}}{-2\left(A_{t}\right)(M)}\right)
$$

The tendency of body to resist the change in its angular acceleration is known as a moment of inertia that is equal to the sum of the products of the mass of each particle in the body with the square of its distance from the axis of rotation. Accordingly,

$$
I=\frac{1}{3} m L^{2}
$$

where $m$ is the mass of nose landing gear and $L$ is the full length of strut from axis of rotation. Accordingly, this inertia times the angular acceleration that is needed in strut must be balanced by the force in the actuator and moment produced against the motion due to effect of gravity,

$$
\begin{gathered}
\Sigma M=I \alpha=(F)(M) \sin (\phi)-m g\left(l_{c g}\right) \sin (90-\theta) \\
F=\frac{I \alpha+m g\left(l_{c g}\right) \sin (90-\theta)}{(M) \sin (\phi)}
\end{gathered}
$$

where $l_{c g}$ is the length of strut from axis of rotation to center of gravity and $g$ is the gravitational acceleration. The force that is required by the actuator at any time, $t$, to retract the landing gear into its position can be found from the Equation (16),

$$
F=\frac{1 / 3\left(m L^{2}\right)\left[\frac{c \pi}{180}\left(2 t-t_{\max }\right)\right]+m g l_{c g} \sin \left[90-\theta_{1}+c\left(\frac{t^{3}}{3}-\frac{t^{2} t_{\max }}{2}\right)\right]}{(M) \sin \left[\cos ^{-1}\left(\frac{D^{2}-M^{2}-A_{t}^{2}}{-2\left(A_{t}\right)(M)}\right)\right]}
$$

The maximum actuator force required for retraction was calculated to be $2200 \mathrm{~N}$, However, for the calculation of power, force $(F)$ was multiplied with translational velocity $V_{s}$. Non-linear variation of stroke, translational velocity, and power calculated by using Equations (7), (9), and (16) is shown in Figure 4. The maximum stroke of $36.24 \mathrm{~cm}$, velocity of $3.9 \mathrm{~cm} / \mathrm{s}$, and power of 27 watt, were observed during retraction cycle of NLG. Non liner behaviour of these parameter shows that the lading gear will slowly start to retract and reach its maximum velocity after $7.5 \mathrm{~s}$ and then its velocity will start to decrease in the next $7.5 \mathrm{~s}$. If retraction cycle would have designed in such a way that the velocity increases gradually, then a lot of stresses would have introduced at the strut-actuator due to sudden jerk at the start of retraction, which is usually not considered as a safe practice during design, so, for the purpose of controlling the velocity, the retraction algorithm must be designed in order to achieve the non-linear velocity curve, as shown in Figure 4. 


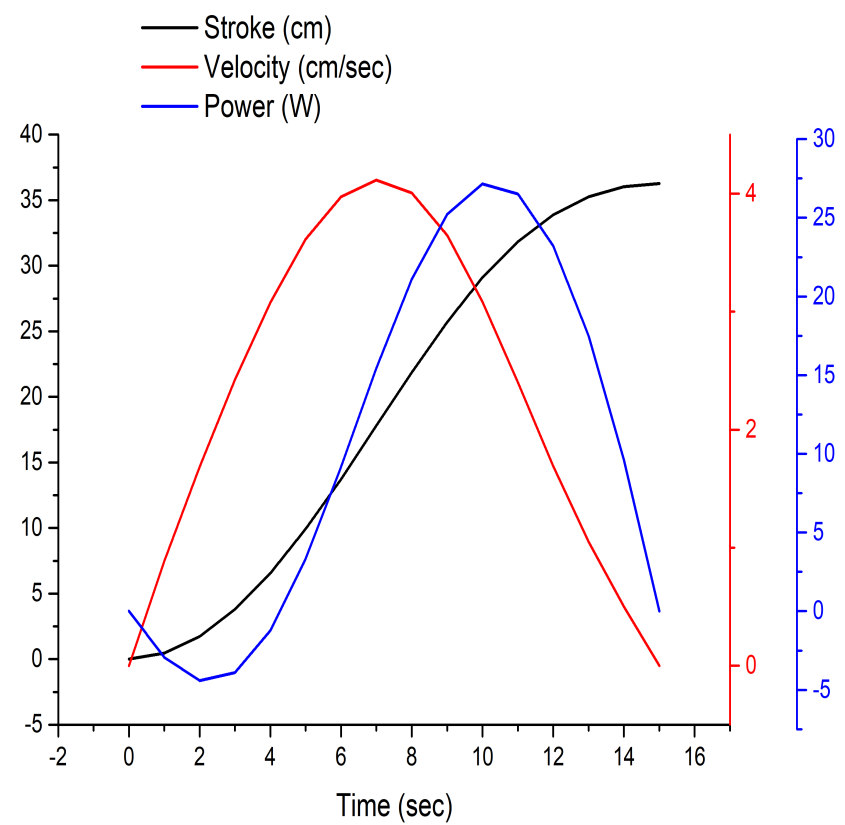

Figure 4. Analytical evaluation of Stroke, Velocity, and Power for Nose Landing Gear.

\subsection{Computational Analysis Using MSC ADAMS}

The retractable landing gear system is an integrated system that consists of landing gear structure, a complicated locking mechanism, door mechanism, and landing gear control module. It has to meet the retraction/extension time requirement; therefore, as a result, a comprehensive model is required in order to evaluate the performance of system and figure out the load on actuators, door links, and some of the important joints. The modeling of such an integrated system while using any of commercially available multibody dynamic software presents an exceptional strategy to this challenging requirement and it results in time saving for the system development [20]. In the past few years, multibody softwares have been successfully employed for the prediction of landing gear (LG) dynamic behaviour [21]. There are various open-source free softwares available in the market for carrying out the analysis, like MBDyn, Solfec, and MBSim. However, in this research work, MSC ADAMS ${ }^{\circledR}$ was used for computational analysis. During analysis, ADAMS Solver describes the direction and location of every part in the mechanical system in terms of six degree of freedom. ADAMS Solver stores angular displacements and time-dependent translational accelerations and velocities in the form of state vector. The state vector consists of current values for the applied forces and their reaction on every part at the inertial locations. Thus, the state vector provides a complete description of the mechanical system for simulation [22]. In this paper, the dynamic performance of landing gear for the duration of retraction operations is examined with the help of ADAMS. It allows for graphical construction of a model with real geometry and joints having same degrees of freedom, as they do in the actual case. The dynamic properties are represented by the masses and rotational inertia that are attached to the components.

\subsubsection{Calculation of Stroke, Velocity and Power}

In MSC ADAMS ${ }^{\circledR}$ problem was setup in the work space and constraints were defined along with forces applied on the CAD model, refer to Figures 5 and 6 . After setting up the problem, dynamic analysis was implemented on the nose landing gear in order to find out the power required by the actuator for retraction in $15 \mathrm{~s}$. The Landing Gear was retracted by 88 degrees in $15 \mathrm{~s}$ on MSC $\mathrm{ADMAS}^{\circledR}$, as shown in Figure 7. The graphs as shown in Figure 8 were plotted for actuator stroke, translational velocity, and power consumption across time on the $x$ axis. It can be observed that when landing gear is initially fully extended, time is taken to be $0 \mathrm{~s}$. Actuator needs a stroke of $0.363 \mathrm{~m}$ 
$(36.3 \mathrm{~cm})$ for the nose landing gear to reach the fully retracted position. Initially, the velocity is zero at fully extended position, but, as the gear starts to retract, the velocity increases until it reaches the maximum velocity of $0.0365 \mathrm{~m} / \mathrm{s}(3.65 \mathrm{~cm} / \mathrm{s})$ at $7.5 \mathrm{~s}$ and then starts to decrease as the landing gear reaches it fully retracted position at $15 \mathrm{~s}$. The maximum force required came out to be $2273 \mathrm{~N}$, with a power requirement of 27.98 watt. The maximum power required during analysis is at $11.25 \mathrm{~s}$ of retraction cycle. It is concluded that maximum velocity and maximum power did not occur at same time for landing gear retraction, since there are other factors that also contribute to the power required for the retraction.

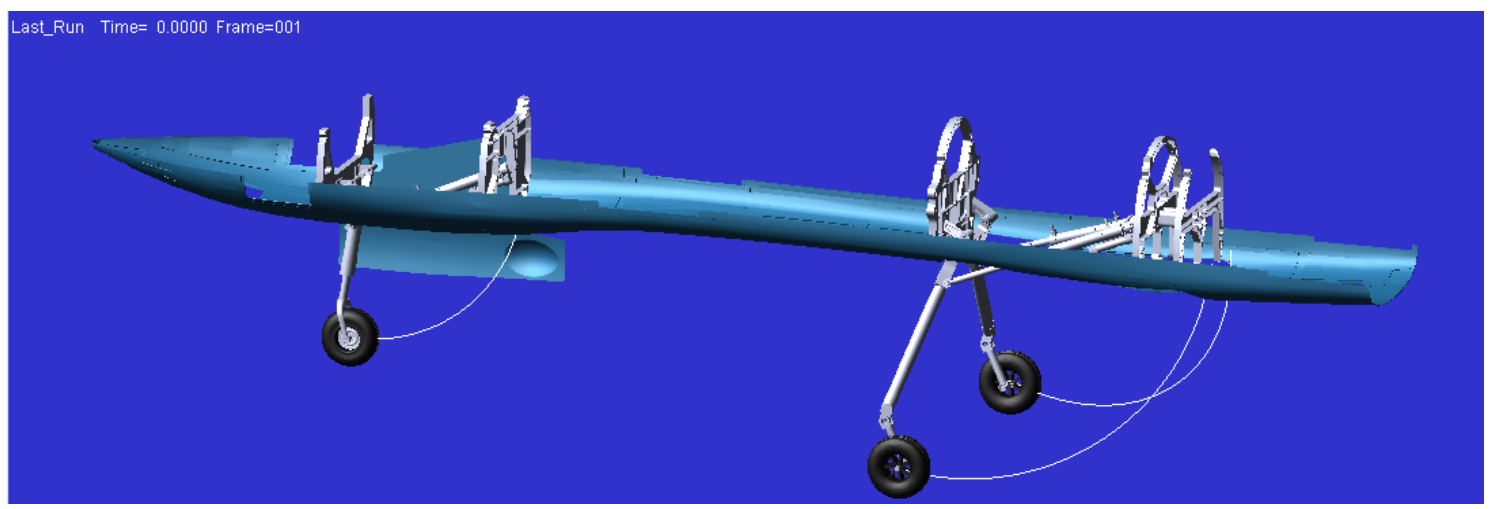

Figure 5. Modelling of aircraft with landing gears in extended configuration.

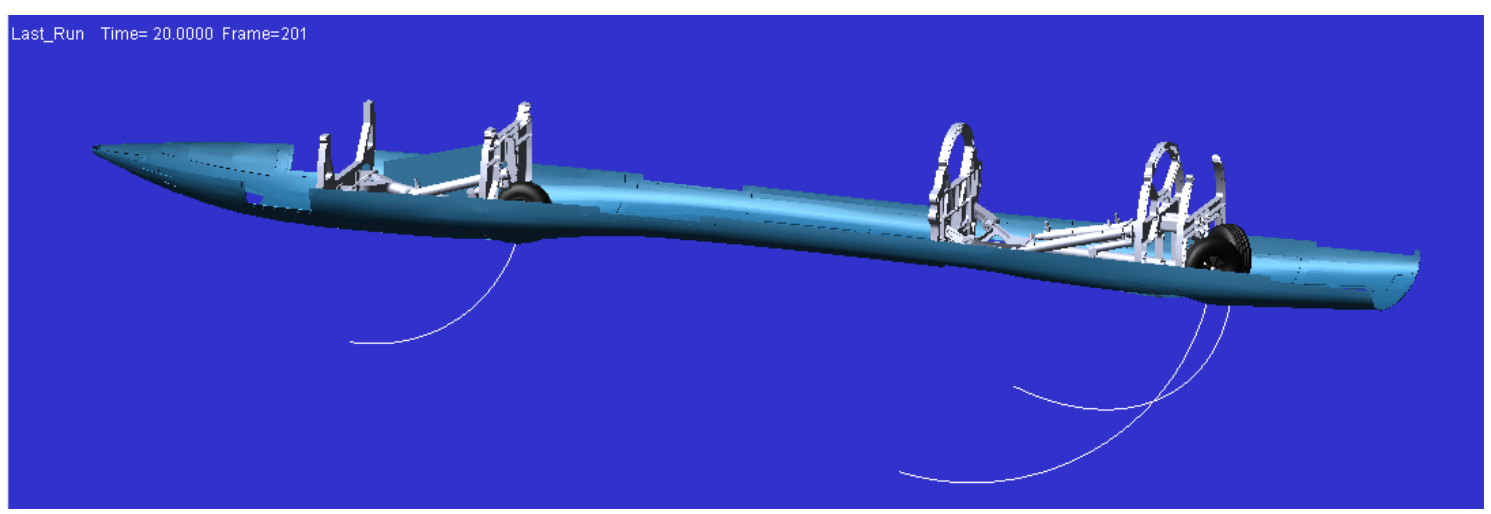

Figure 6. Modelling of aircraft with landing gears in retracted configuration.

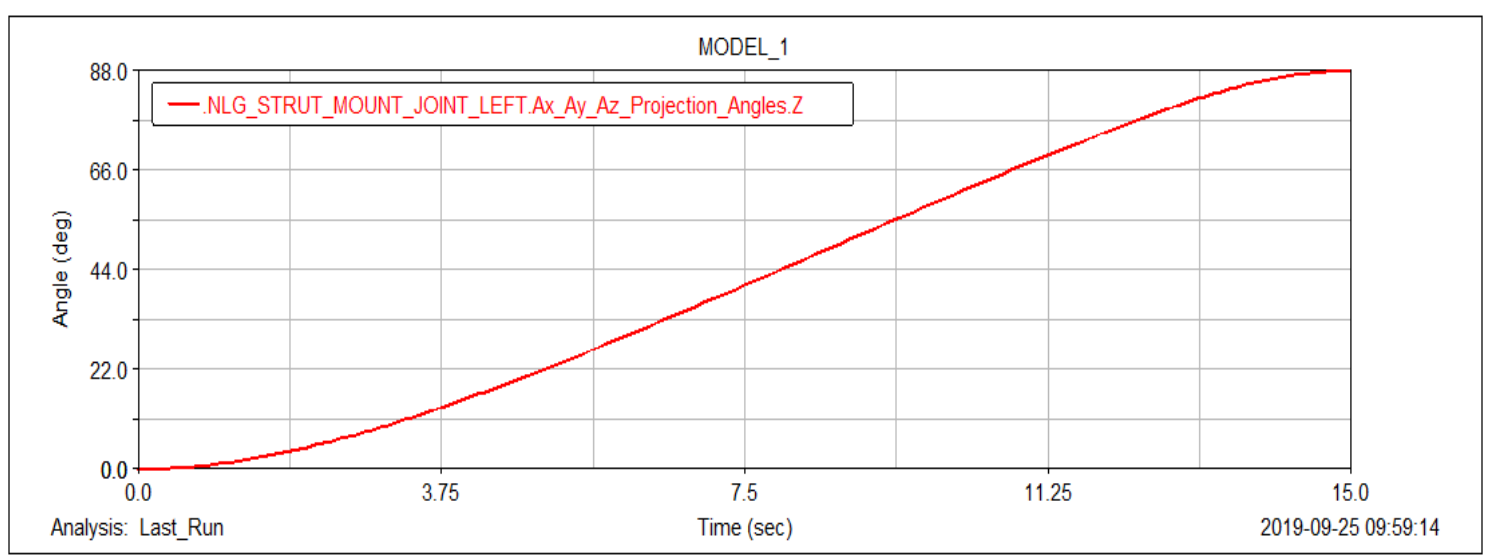

Figure 7. Computational result of retraction angle variation with time. This figure shows a total of $15 \mathrm{~s}$ are required for complete retraction of landing gear by 88 degree. 


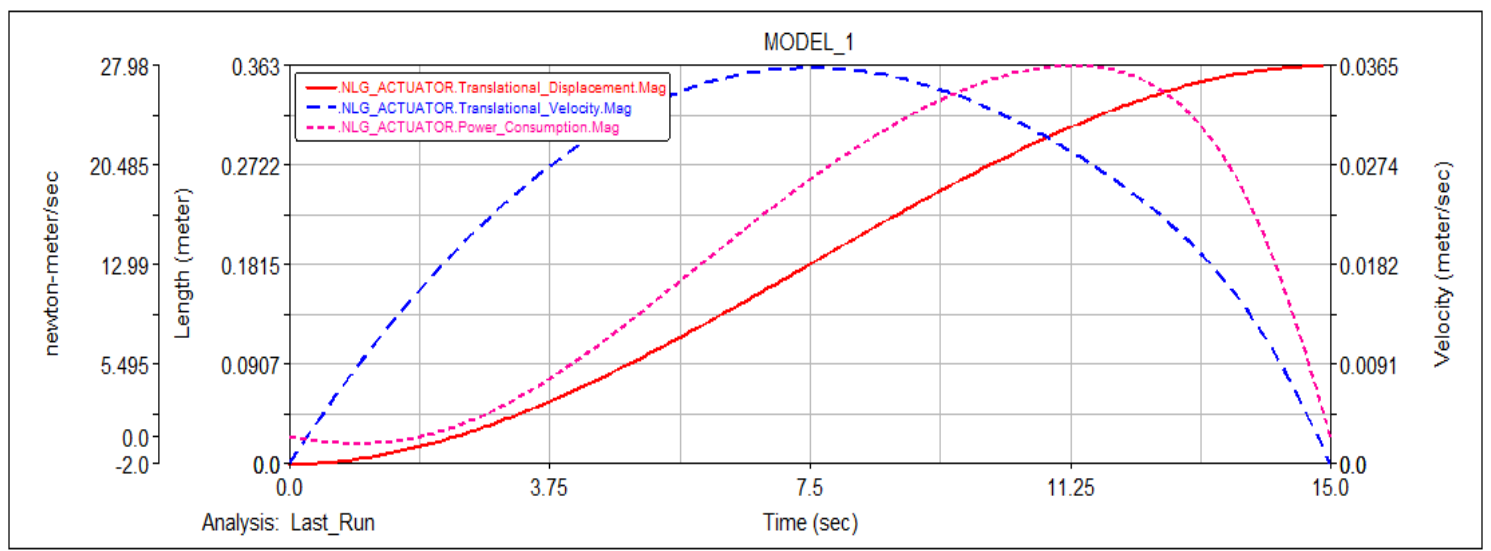

Figure 8. Computational evaluation of Stroke, Velocity and Power with time. Maximum velocity of $3 \mathrm{~cm} / \mathrm{s}$ was achieved in the middle of retraction cycle after $7.5 \mathrm{~s}$.

The results from both the methods (computational and analytical) are compared in Table 2, and it was found that analytical expressions derived for the retraction cycle yields almost same results as the computational method. The retraction angle for both of the methods was $88^{\circ}$ in $15 \mathrm{~s}$. The error in stroke was calculated to be $0.16 \%$, while it was $6.4 \%$ for maximum translational velocity. The maximum power and force requirement were also calculated with acceptable error of $3.31 \%$ and $3.62 \%$, respectively. This verifies the authenticity of analytical expressions derived. Because analytical solution methods are usually limited to highly simplified problem in simple geometries, there is much less possibility that they can yield exactly the same results as the computational method.

Table 2. Results Comparison.

\begin{tabular}{lccc}
\hline Parameter & Analytical Value & Computational Value & Error \\
\hline Retraction Angle & $88^{\circ}$ & $88^{\circ}$ & - \\
Retraction Time & $15 \mathrm{~s}$ & $15 \mathrm{~s}$ & - \\
Stroke & $36.24 \mathrm{~cm}$ & $36.3 \mathrm{~cm}$ & $0.16 \%$ \\
Maximum Translational velocity & $3.9 \mathrm{~cm} / \mathrm{s}$ & $3.65 \mathrm{~cm} / \mathrm{s}$ & $6.4 \%$ \\
Maximum Force & $2200 \mathrm{~N}$ & $2273 \mathrm{~N}$ & $3.31 \%$ \\
Maximum Power & 27 watt & $27.98 \mathrm{watt}$ & $3.62 \%$ \\
\hline
\end{tabular}

\subsection{Actuator Locking Load}

One of the functions of actuator other than the retraction is to keep the landing gear retracted with the help of some locking mechanism internally or externally, which must be able to sustain the impacts during landing and restrict any moment produced in the landing gear strut to retract it. The following loads will try to generate moment in landing gear strut once it touches the ground during landing, refer Figure 9.

- A component of impact load; landing gear strut is at an angle of 7.61 degree with respect to vertical axis.

- Dynamic braking load. 


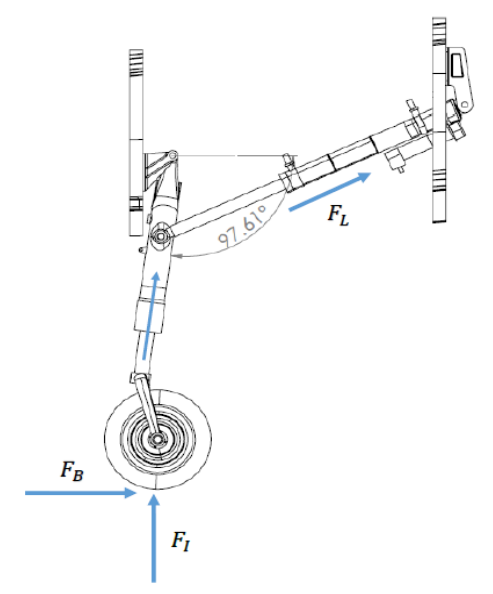

Figure 9. Forces acting on nose landing gear strut. Impact force $\left(F_{I}\right)$, Braking force $\left(F_{B}\right)$, Axial force $\left(F_{L}\right)$ acted on actuator at touchdown.

\subsection{Oleo-Pneumatic Strut and Drop Test}

The landing gear under consideration for retraction is an Oleo-Pneumatic type. An oleo pneumatic strut works in a different way when compared to the conventional spring. There are two chambers in the assembly that are connected by an orifice and separated by diaphragm. Oil is filled in the lower chamber while the upper chamber is filled partially by air and partially by oil. When the piston moves in cylinder the strut is compressed, oil from the lower chamber flows in upper chamber through an orifice that produces the damping response, whereas the spring effect is produced due to the compression of air in the upper chamber [23].

\subsection{Air Spring Force}

In the oleo-pneumatic shock absorber, air is mainly used to store part of the absorbed impact energy [24]. The air spring force is influenced by a lot of factors, refer Equation (17), whereas hydraulic force during compression is given by Equation (18).

$$
\begin{gathered}
F_{a}=A_{p}\left[P_{o}\left(\frac{V_{o}}{V_{o}-A_{p} S}\right)^{\gamma}-P_{a t m}\right] \\
F_{H}=\rho\left(\frac{A_{p}^{3}}{2\left(\alpha_{D} A_{\text {orifice }}\right)}+\frac{n \cdot A_{\text {piston-at-rebound }}^{3}}{2\left(\alpha_{\text {Dr }} A_{\text {Rebound-orifice }}\right)^{2}}\right) \dot{S}|\dot{S}|
\end{gathered}
$$

Details of variables used for the calculation of these forces are provided in the nomenclature section. The pressure in the upper chamber of oleo-pneumatic only depends on the air volume and, hence, on the position of the piston. As the strut compresses, pressure increases, while volume decreases. Accordingly, if the initial pressure and volume is known for the strut, then the pressure and volume can be calculated through out the compression stroke by using the Equations (19) and (20). Where $\gamma$ is a polytropic constant and defines the iso-thermal or ploytropic behaviour of gas in the equations. Iso-thermal compression is observed while taxiing, because, during taxi, the compression is slow and there is much time for heat exchange, while ploytropic compression is observed during impact, because, at that time, strut undergoes very fast compression.

$$
\begin{gathered}
V=V_{o}-\left(\pi \times\left(P_{\text {dia }} / 2\right)^{2} \times S\right) \\
P=P_{o} \times\left(V_{o} / V\right)^{\gamma}
\end{gathered}
$$

To find out the impact loads on landing gear, a drop test was conducted while using the MSC ADAMS $^{\circledR}$. For modeling the behavior of oleo-pneumatic, a nonlinear spring was modeled in the MSC 
ADAMS $^{\circledR}$, which reflected the properties nonlinear pressure in the system as shown in Figure 10, whereas, for the purpose of damping characteristics, a nonlinear curve for the damping constant was defined. ADAMS formulate a Lagrange equation of motion that leads to the second order differential equation. These differential equations are called kinetic differential equations, and it regards the external forces and their influence according to the time variation [25].

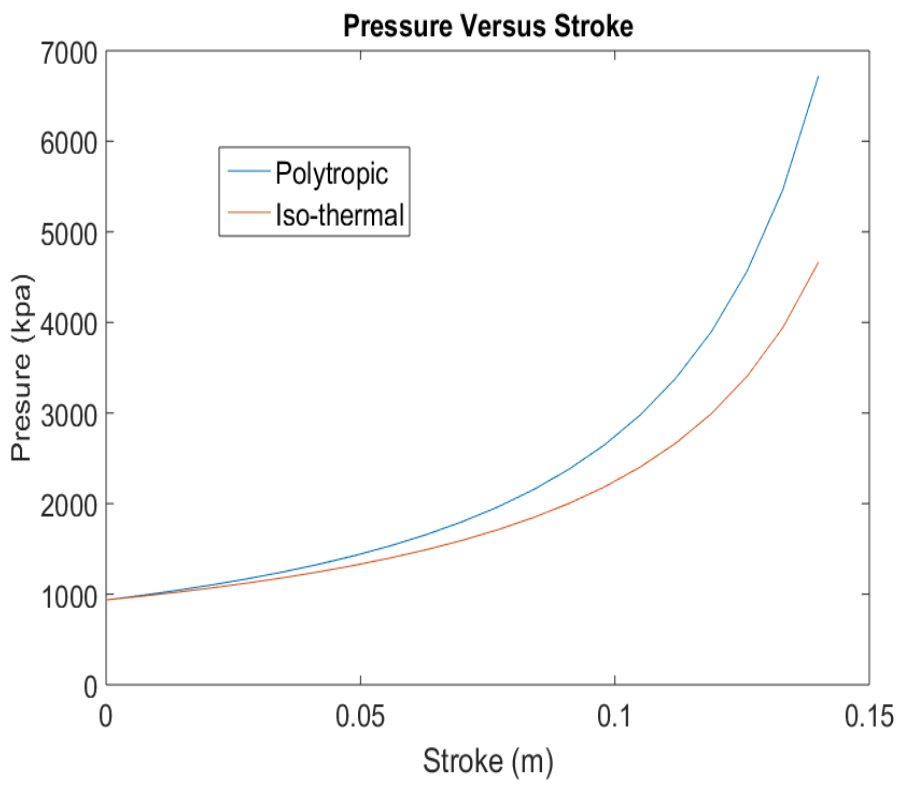

Figure 10. Iso-thermal and Polytropic behavior of Oleo Pneumatic Strut.

An equivalent drop height was also calculated in order to accurately simulate the drop test of landing gear by using law of conservation of energy, which leads to Equation (21).

$$
H=\frac{W_{L} V^{2}}{W_{g} 2 g}
$$

where $W_{L}$ is weight of aircraft at landing and $W_{g}$ weight of landing gear. As per aircraft specifications, approximately $15 \%$ of the total weight of an aircraft acts on the nose wheel [26]. For the purpose of a drop test, landing gear was fixed in the test rig and a dummy weight equal to $15 \%$ ( $240 \mathrm{~kg})$ of aircraft total weight at time of landing was therefore applied. The drop height was calculated to be $0.32 \mathrm{~m}$ for the aircraft vertical landing speed of $2.5 \mathrm{~m} / \mathrm{s}$. After calculating the equivalent drop height, spring characteristics, and damping constant, the landing gear was tested in MSC ADAMS ${ }^{\circledR}$ software, Figure 11 shows the assembly setup for drop test.
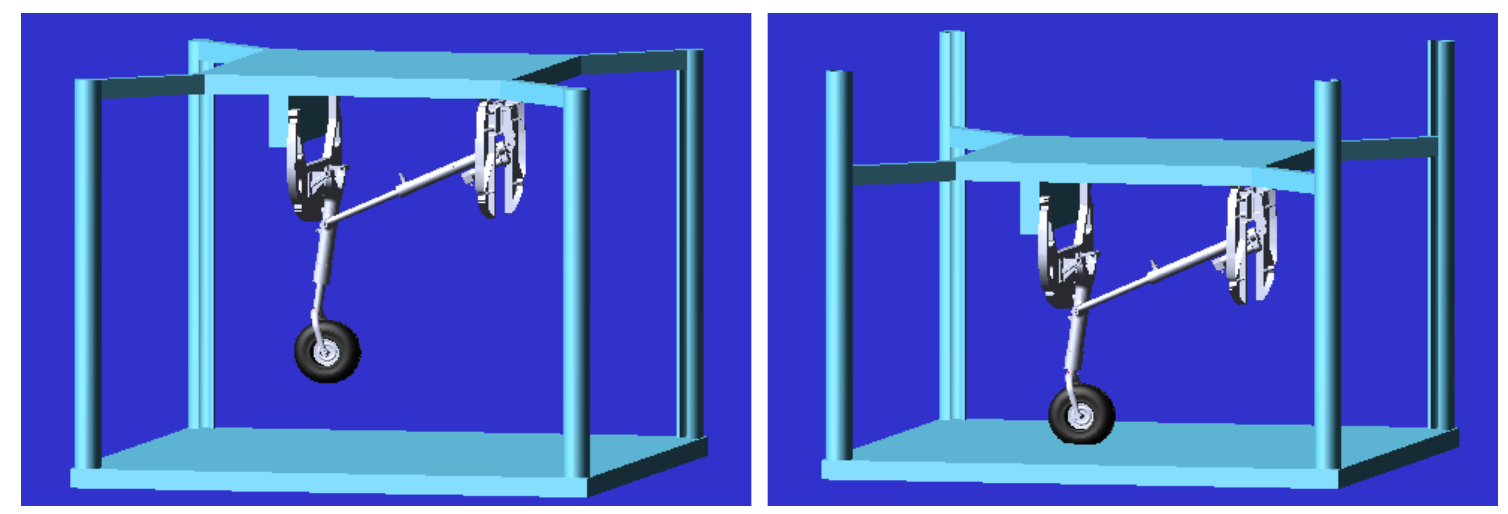

Figure 11. Drop test setup design, modelling, \& simulation. 
Time-dependent nose landing gear shock absorber responses are shown in the form of the reaction forces being generated in vertical direction for normal $15 \%$ weight on the nose landing gear at different landing weights of aircraft Figure 12. The aircraft under study is a light weight long endurance aircraft with fuel capacity of $380 \mathrm{~kg}$. Accordingly, the first case was studied at a maximum takeoff weight of aircraft, while the second case was studied for the landing after consuming half of the aircraft fuel and third case was studied for the landing after consuming all of the aircraft fuel. It can be observed that the shock absorber significantly dampens the initial impact in $0.15 \mathrm{~s}$. The final case for the hard landing was considered with $20 \%$ aircraft weight on the nose landing gear, the shock absorber was fully collapsed, which suggested that it is beyond the capability of oleo-pneumatic to sustain that much load. Figure 13 shows the behavior of shock absorber in the hard landing case.

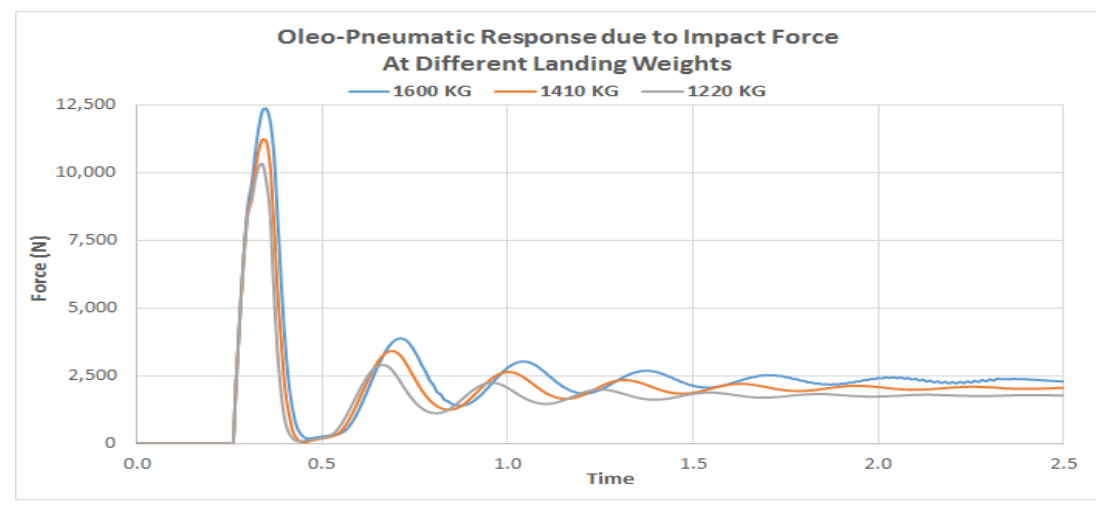

Figure 12. Vertical impact force recorded during drop test simulation.

Because landing strut is at an angle of $7.61 \mathrm{deg}$ with respect to vertical axis in extended configuration so, if $F_{I}$ is the impact force from ground then a component of impact force $F_{I} \cos (\theta)$ will create a clockwise moment in the landing gear strut while $F_{I} \sin (\theta)$ will act in the direction of landing gear strut. Additionally, longitudinal loads $\left(F_{B}\right)$ also act on the landing gear strut due to which an anticlockwise moment is produced in the landing gear. Longitudinal loads during landing are due to 'spin up' loads, braking and rolling friction [27]. Instantly after the touchdown, the ground friction provides torque to accelerate the wheel from static to matching landing speed in just a fraction of seconds during this time the wheel slides for a while which creates horizontal impact on the landing gear [28]. The horizontal impact in MSC ADAMS was recorded by rotating the wheel of landing gear to match the speed of aircraft, so that, when wheel touches the stationary platform, it should produce nearly the same effect as the plane landing on runway. For the landing at maximum takeoff weight the resultant of all the moments and forces due to them, acting in the axial direction of actuator were calculated and plotted against time in the Figure 14.

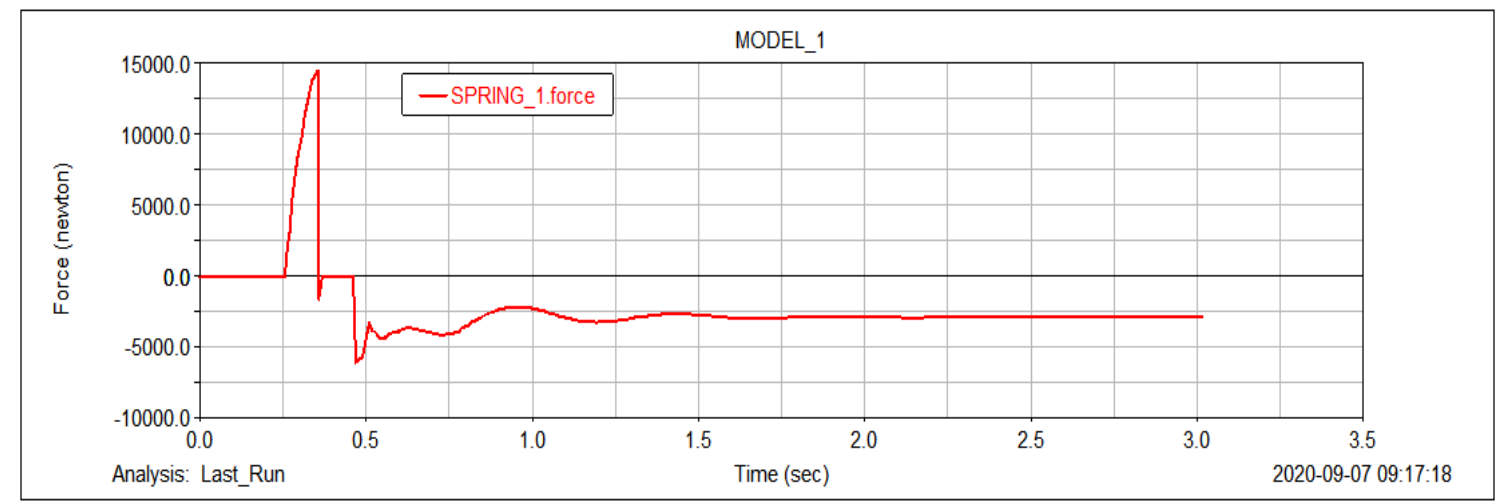

Figure 13. Vertical impact force computed form hard landing case simulation at $20 \%(320 \mathrm{~kg})$ of aircraft maximum takeoff weight on nose landing gear. 


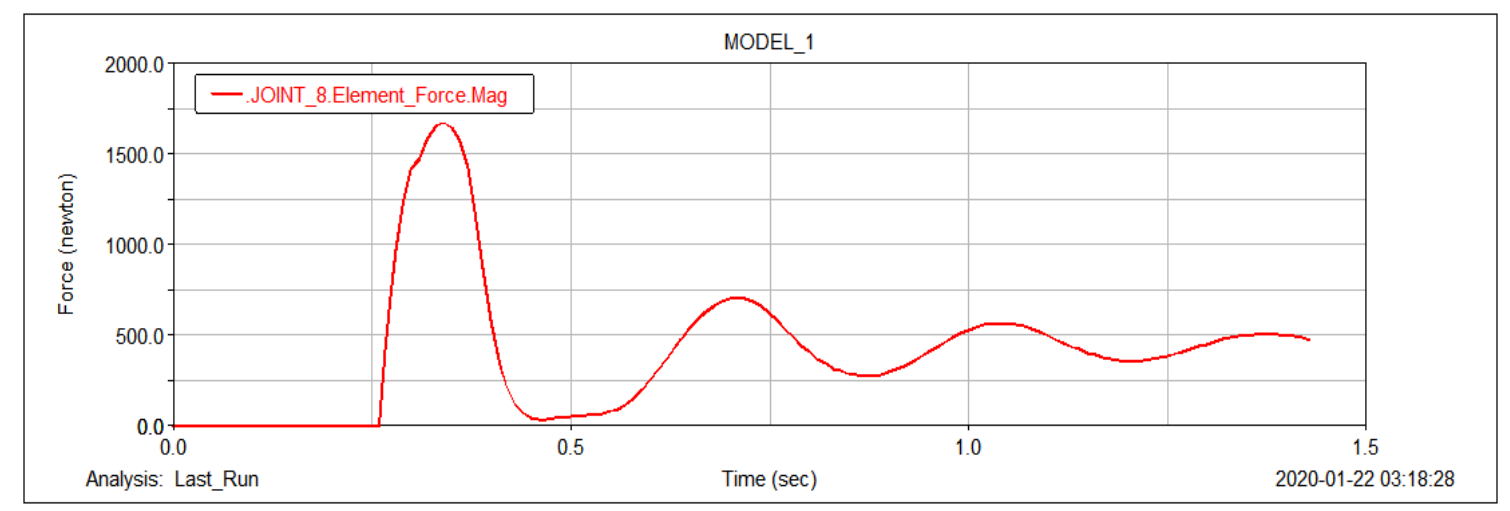

Figure 14. Actuator locking load evaluation during impact simulation. This figure shows variation of axial force with time acting on actuator during impact simulation.

It was found that the maximum load acting in the axial direction of actuator $\left(F_{L}\right)$ is $1600 \mathrm{~N}$. The actuator design has to make sure that, under these loads, the landing gear will remain extended and the loads will not cause any misalignment of actuator with strut joint due to deformation. However, in case if the loads exceeds the maximum force to which an actuator can withstand, an additional locking mechanism must be developed beside the actuator locking for added safety and certification process.

\section{Conclusions}

A comprehensive study for solving the kinematics of landing gear have been presented in this work and various parameters for the actuator have been calculated theoretically as well as using MSC ADAMS ${ }^{\circledR}$. The results for both of the methods were found to be in good agreement with each other. The landing gear was retracted, as per the design constraints that are given in Table 1. Various parameters for the actuator, like stroke, translational velocity, and force were calculated. The maximum force and power requirement came out at different time during retraction cycle. It is concluded that maximum velocity, force and power do not occur at same time during landing gear retraction cycle, since there are other factors that are also contributing to the power required for the retraction. When landing gear reaches its maximum retracted position the force required is maximum, because maximum gravitational force is acting on the landing gear at that time due to its horizontal position, while the required power is not maximum, because the velocity of landing gear actuation is not maximum, rather it is close to zero as the landing gear is about to complete its actuation cycle. The detailed design phase of actuator must consider all of the parameters calculated in this work. Moreover, a methodology for the drop test on MSC ADAMS ${ }^{\circledR}$ has been proposed in the paper, after modelling the oleo-pneumatic, which resulted in the calculation of locking loads on actuator. The actuator design must take into consideration the component of impact force along the axis of actuator. After thorough analysis, as presented in this paper, it is concluded that the developed retraction kinematics meet all of the requirements of retraction cycle and safety for the present case study of Nose Landing Gear and the actuation can be carried out with an electrical actuator. The design has been successfully tested on a scale down model. The proposed landing gear actuation system will increase the aircraft performance with a substantial reduction in drag through retraction. Moreover multibody dynamic software are not only helpful in solving the kinematics of landing gear but they are also useful in modeling the behaviour of landing gear strut during impact. The analytical equations that are derived in this work are helpful in for solving the kinematics of any similar mechanisms, and both the computational and analytical method utilized in the paper verify the authenticity of each other, since the error recorded between them was almost negligible. 


\section{Future Work}

The current research proposed a kinematic design for the retraction of landing gear, as per the civil aviation regulations, after calculating all the requirements of the actuator design. It is highlighted that the next phase of design process will include the actuator design for this kinematics that are based on the calculated parameters. Additionally, landing gear emergency extension under effect of gravity is one of the biggest challenges for electro-mechanical actuators, because the cylinder cannot be set free to extend under the gravity forces. A standby motor can be installed for emergency lowering in the case of primary motor malfunction. However, in the case of control circuit malfunction or complete electric failure, a standby motor will not work. This is an area of open research for electrically actuated landing gear systems and it will be addressed in the next detailed design phase of aerospace standard actuator by the authors.

Author Contributions: Conceptualization, methodology and final write-up, T.A.S.; Funds acquisition and supervisor of research work, S.I.A.S.; project administration, M.A.A.; Resources, K.M.; Software, results validation, W.A.; Proof reading, S.T.u.I.R. All authors have read and agreed to the published version of the manuscript.

Funding: This research work was funded by Higher Education Commission (HEC) of Pakistan vide HEC grant number TDF 03-331 and National University of Sciences and Technology, Islamabad, Pakistan.

Conflicts of Interest: The authors declare no conflict of interest. Further the funders had no role in the design of the study; in the collection, analyses, or interpretation of data; in the writing of the manuscript, or in the decision to publish the results.

\section{Nomenclature}

$\begin{array}{lll}\text { Nomenclature } & \text { Description } & \text { Value/Unit } \\ \theta_{1} & \text { Initial angle of landing gear when fully extended } & \text { degree } \\ \Delta \theta_{t} & \text { Change in angle of landing gear at any given time t } & \text { degree } \\ t_{\text {max }} & \text { Maximum time in which the landing gear has to retract } & \mathrm{s} \\ \mathrm{C} & \text { Constant and its value can be found from our desired inputs } & - \\ A_{t} & \text { Length of actuator at any time t } & \mathrm{cm} \\ \mathrm{D} & \text { Distance between actuator mount and landing gear strut mount } & \mathrm{cm} \\ \mathrm{M} & \text { Moment arm } & \mathrm{cm} \\ S_{A} & \text { Stroke of actuator } & \mathrm{cm} \\ V_{S} & \text { Translational velocity of actuator } & \mathrm{cm} \\ \mathrm{F} & \text { Force required for retraction } & \mathrm{N} \\ \mathrm{m} & \text { Mass of strut } & \mathrm{Kg} \\ \mathrm{L} & \text { Length of strut from axis of rotation } & \mathrm{cm} \\ \mathrm{g} & \text { Gravitational acceleration } & \mathrm{cm} / \mathrm{s}^{2} \\ l_{C G} & \text { Length of strut from its axis of rotation to center of gravity } & \mathrm{cm} \\ \mathrm{P} & \text { Power required by actuator } & \mathrm{Watt} \\ A_{p} & \text { Hydraulic area of piston } & 0.00156 \mathrm{~m}^{2} \\ P_{o} & \text { Initial extended pressure of air } & 0.6 \mathrm{MPa} \\ V_{o} & \text { Initial volume of air } & 2.90 \times 10^{-4} \mathrm{~m}^{3} \\ S & \text { Stroke length of strut } & 0.14 \mathrm{~m} \\ P_{\text {dia }} & \text { Piston Diameter } & 0.045 \mathrm{~m} \\ \gamma & \text { Polytropic coefficient } & 1.35 \mathrm{or} 1 \\ P_{\text {atm }} & \text { Atmospheric pressure } & 101,325 \mathrm{~Pa} \\ \rho & \text { Density of hydraulic fluid } & 839.3 \mathrm{Kg} / \mathrm{m}^{3} \\ D & \text { Discharge Coefficient } & 0.76 \\ A_{\text {orifice }} & \text { Area of orifice } & 0.0000420 \mathrm{~m}^{2} \\ n & \text { Number of orifices } & 8 \\ A_{\text {piston-at-rebound }} & \text { Area of piston at rebound } & 0.000597 \mathrm{~m}^{2} \\ \alpha_{D} & \text { Discharge coefficient of rebound } & 0.79 \\ A_{\text {rebound-orifice }} & \text { Area of rebound orifice } & 0.0000701 \mathrm{~m}^{2} \\ S & \text { Telescoping velocity } & 2.5 \mathrm{~m} \\ & & \end{array}$




$\begin{array}{lll}H & \text { Drop height } & 0.32 \mathrm{~m} \\ V & \text { Horizontal velocity (at touchdown) } & 45 \mathrm{~m} / \mathrm{s} \\ \mu & \text { Coefficient of friction (at touchdown) } & 0.6 \\ \text { Stiffness } & \text { Base-Tyre contact stiffness } & 10^{-8} \mathrm{~N} / \mathrm{m} \\ F_{\text {air }} & \text { Air spring force } & \mathrm{N} \\ F_{\text {hydraulic }} & \text { Hydraulic damping force } & \mathrm{N} \\ F_{I} & \text { Vertical impact force } & \mathrm{N} \\ F_{L} & \text { Axial force acting on actuator at touchdown } & \mathrm{N} \\ F_{B} & \text { Dynamic braking load at touchdown } & \mathrm{N}\end{array}$

\section{References}

1. Hameed, A.; Zubair, O.; Shams, T.A.; Mehmood, Z.; Javed, A. Failure analysis of a broken support strut of an aircraft landing gear. Eng. Fail. Anal. 2020, 117, 104847. [CrossRef]

2. Divakaran, V.; Ravi Kumar, G.; Srinivasa Rao, P. Aircraft Landing Gear Design E Development_-How Advanced Technologies Are Helping to Meet the Challenges; White Paper; Infosys Limited: Bangalore, India, 2015.

3. Götten, F.; Finger, D.; Havermann, M.; Braun, C.; Gomez, F.; Bil, C. On the Flight Performance Impact of Landing Gear Drag Reduction Methods for Unmanned Air Vehicles; In Proceedings of the Deutscher Luft- und Raumfahrtkongress 2018_DLRK 2018, Friedrichshafen, Germany, 4-6 September 2018.

4. Chun-Yung, N.M. Airframe Structural Design-Practical Design Information and Data on Aircraft Structures; AD Adaso/Adastra Engineering LLC: Northridge, CA, USA, 1999.

5. Jean-Charles, M.; Jian, F. Review on signal-by-wire and power-by-wire actuation for more electric aircraft. Chin. J. Aeronaut. 2017, 30, 857-870.

6. Li, W.; Fielding, J. Preliminary study of EMA landing gear actuation. In Proceedings of the 28th International Congress of the Aeronautical Sciences, Brisbane, Australia, 23 September 2012; pp. 23-28.

7. Janker, P.; Claeyssen, F.; Grohmann, B.; Christmann, M.; Lorkowski, T.; LeLetty, R.; Sosniki, O.; Pages, A. New actuators for aircraft and space applications. Proc. Actuator 2006, 325-330.

8. Botten, S.L.; Whitley, C.R.; King, A.D. Flight control actuation technology for next-generation all-electric aircraft. Technol. Rev. J. 2000, 8, 55-68.

9. Qiao, G.; Liu, G.; Shi, Z.; Wang, Y.; Ma, S.; Lim, T.C. A review of electromechanical actuators for More/All Electric aircraft systems. Proc. Inst. Mech. Eng. Part C J. Mech. Eng. Sci. 2018, 232, 4128-4151. [CrossRef]

10. Tamer, A.; Masarati, P. Sensitivity of Lyapunov Exponents in Design Optimization of Nonlinear Dampers. J. Comput. Nonlinear Dyn. 2019, 14, 021002 . [CrossRef]

11. Tourajizadeh, H.; Zare, S. Robust and optimal control of shimmy vibration in aircraft nose landing gear. Aerosp. Sci. Technol. 2016, 50, 1-14. [CrossRef]

12. European Aviation Safety Agency. Certification Specifications for Normal, Utility, Aerobatic, and Commuter Category Aeroplanes-CS-23; European Aviation Safety Agency: Cologne, Germany, 2012.

13. Boniol, F.; Wiels, V. The landing gear system case study. In Proceedings of the International Conference on Abstract State Machines, Alloy, B, TLA, VDM, and Z, Toulouse, France, 2 June 2014.

14. Krakowska, A. Design of retraction mechanism of aircraft landing gear. Mech. Mech. Eng. 2008, 12, $357-373$.

15. Goodman, J. Principles of Scientific Computing Sources of Error. Available online: https://www.math.nyu. edu/faculty/goodman/teaching/SciComp2003/Book/sourcesOfError.pdf (accessed on 6 January 2006).

16. Meriam, J.L.; Glenn Kraige, L. Engineering Mechanics: Dynamics; John Wiley \& Sons: Hoboken, NJ, USA, 2012; Volume 2.

17. Currey, N.S. Aircraft Landing Gear Design: Principles and Practices; American Institute of Aeronautics and Astronautics: Reston, VA, USA, 1988.

18. Roskam, J. Airplane Design: Layout Design of Landing Gear and Systems; Design Analysis \& Research; Roskam Aviation and Engineering Corporation: Lawrence, KS, USA, 1989.

19. Chakraborty, I.; Jackson, D.; Trawick, D.R.; Mavris, D. Development of a sizing and analysis tool for electrohydrostatic and electromechanical actuators for the more electric aircraft. In Proceedings of the 2013 Aviation Technology, Integration, and Operations Conference, Los Angeles, CA , USA, 12-14 August 2013; p. 4282. 
20. Khapane, P. Simulation of Aircraft Landing Gear Dynamics Using Flexible Multibody Dynamics Methods in Simpack. In Proceedings of the ICAS 2004, Yokohama, Japan, 29 August-3 September 2004.

21. Gualdi, S.; Morandini, M.; Ghiringhelli, G.L. Anti-skid induced aircraft landing gear instability. Aerosp. Sci. Technol. 2008, 12, 627-637. [CrossRef]

22. Li, Z.; Kota, S. Virtual prototyping and motion simulation with ADAMS. J. Comput. Inf. Sci. Eng. 2001, 1, 276-279. [CrossRef]

23. Flugge, W. Landing-Gear Impact; Technical Report; National Aeronautics and Space Administration: Washington, DC, USA, 1952.

24. Chartier, B.; Tuohy, B.; Retallack, J.; Tennant, S. Landing Gear Shock Absorber. Res. Proj. 2006. Available online: http:/ / www.docstoc.com/docs/21507104/LANDINGGEAR-SHOCK-ABSORBER (accessed on 3 October 2020).

25. Negrut, D.; Harris, B. ADAMS Theory in a Nutshell; Department of Mechanical Engineering, The University of Michigan: Ann Arbor, MI, USA, 2001.

26. Leo, R.; Fenza, A.; Barile, M.; Lecce, L. Drop test simulation for an aircraft landing gear via multi-body approach. Arch. Mech. Eng. 2014, 61, 287-304. [CrossRef]

27. Veetil, M. Determination of Required Torque to Spin Aircraft Wheel at Approach Using ANSYS CFX. Am. J. Aerospace Eng. 2016, 3, 13-23.

28. Wang, W. Dynamics and energy conversion of aircraft landing gears at touchdown. MATEC Web Conf. 2016, 77, 01038. [CrossRef]

Publisher's Note: MDPI stays neutral with regard to jurisdictional claims in published maps and institutional affiliations. 